Proceedings

\title{
Low Cost Micro Milling Machine for Prototyping Plastic Microfluidic Devices ${ }^{\dagger}$
}

\author{
Md Mubarak Hossain and Tanzilur Rahman * \\ Department of Electrical and Computer Engineering, North South University, Dhaka 1229, Bangladesh; \\ mubarak111nsu@gmail.com \\ * Correspondence: tanzilur.rahman@northsouth.edu; Tel.: +02-55668200 \\ † Presented at the Eurosensors 2018 Conference, Graz, Austria, 9-12 September 2018.
}

Published: 4 December 2018

\begin{abstract}
Micro-milling is one of the commonly used methods of fabrication of microfluidic devices necessary for cell biological research and application. Commercial micro-milling machines are expensive, and researchers in developing countries can't afford them. Here, we report the design and the development of a low-cost ( $<130$ USD) micro milling machine and asses the prototyping capabilities of microfeatures in plastic materials. We demonstrate that the developed machine can be used in fabricating the plastic based microfluidicdevice.
\end{abstract}

Keywords: micro milling machine; microfluidic device; biochip; low cost

\section{Introduction}

Microfluidics is an important discipline of science that deals with the design and manufacture of devices with micro precision primarily used for the processing of low volume of fluids for high throughput screening. This area of research has recently attracted scientists from a different discipline such as engineering, physics, chemistry, biotechnology and many more. Research scopes in this area have been increasing day by day due to its multidisciplinary nature [1,2]. Microfluidic devices are fabricated using different materials and their fabrication technologies also vary. Soft photolithography techniques are commonly used for the fabrication of polydimethylsiloxane (PDMS) microfluidic devices but this technique involves multiple steps of fabrication such as mask design, substrate pretreatment, photoresist development, UV exposure etc. Many of these steps require cleanroom environment and are largely done manually. Computer numerical control (CNC) has recently attracted many due to its rapid prototyping ability and one step process of creating multiscale features in a variety of low-cost materials particularly in plastic [3,4].

CNC milling machine thus provides flexibility in design, saves experimental time and allow using poly(methyl methacrylate) (PMMA or acrylic) like materials as a substrate which is available at low cost. Number of ultraprecision milling machines are commercially available that are able to produce high precision micro features. Moore Nanotechnology Nanotech 350FG and Precitecch Freeform 700 ultra are two of the well-known optical component based machining tools widely used in the industry and research laboratories. Both require large space and are too expensive. Kern micro machine is another industrial micro milling machine which is cheaper comparatively but suffers from machining accuracy. Efforts have been given to the research for the development of miniature micro milling machine in the last decade [5,6]. Most of them are still under development, few could reach to the level where they could be used industrial applications but accuracy and surface quality still can be questioned.

However, high accuracy CNC milling machine is expensive and inaccessible to many researchers particularly to those residing in low-income countries. While the costs of such machines may vary depending on the several factors such as precision and speed in designing micro-level features, one could expect to spend at least $\sim 15,000$ USD for a commercially available basic CNC 
machine [3]. This price could rise as high as 200,000 USD based on the characteristics. Laboratories of developing countries can't afford to spend such amount limiting its use for research purpose to those areas.

Here, we propose the design and development of an inexpensive CNC milling machine with entry-level capabilities. The machine has been designed using a computer-based simulation tool and developed within the laboratory setting using the components available in the local market to reduce the cost of the development to under 130 USD. The milling capabilities of the machine have then been assessed by prototyping micro-features in PMMA based plastic. To evaluate the accuracy of the features designed onto PMMA substrate, end mills with different diameters have been used and measured dimensions have been compared with intended dimension. Surface roughness, an important parameter to consider in the application of fabricated microfluidic device has been measured with the help of commercial meters. Fabrication speed of the mechanism and maximum resolution of designed features have also been monitored.

\section{Materials and Methods}

The proposed design (Figure 1) can be divided into three major parts: Software, Control Panel, and Milling Machine. The machine supports varieties of CAD modeling software like Fusion 360, SolidWork, 3D scanner etc. for 3D modeling. At first, the 3D model is converted into printing software readable format (.STL) which is then converted into a series of thin layers (resolution up to $16 \mu \mathrm{m}$ ). The 3D printer starts to print layer by layer using the G-coding. Milling machine is controlled by the main controller (Figure 1) which is connected to the high-speed spindle motor, 3 brushless DC motors, PWM driver and other actuators. The entire system can be controlled from a control panel consisting of a computer (PC) and other I/O peripherals. The total cost of the designed machine (excluding PC) has been estimated to be 125 USD. Most of the hardware parts have been manufactured and assembled in the laboratories in order to reduce the cost of production. Open source software such as G-code and GRBL have been used considering the affordability of lowincome countries.

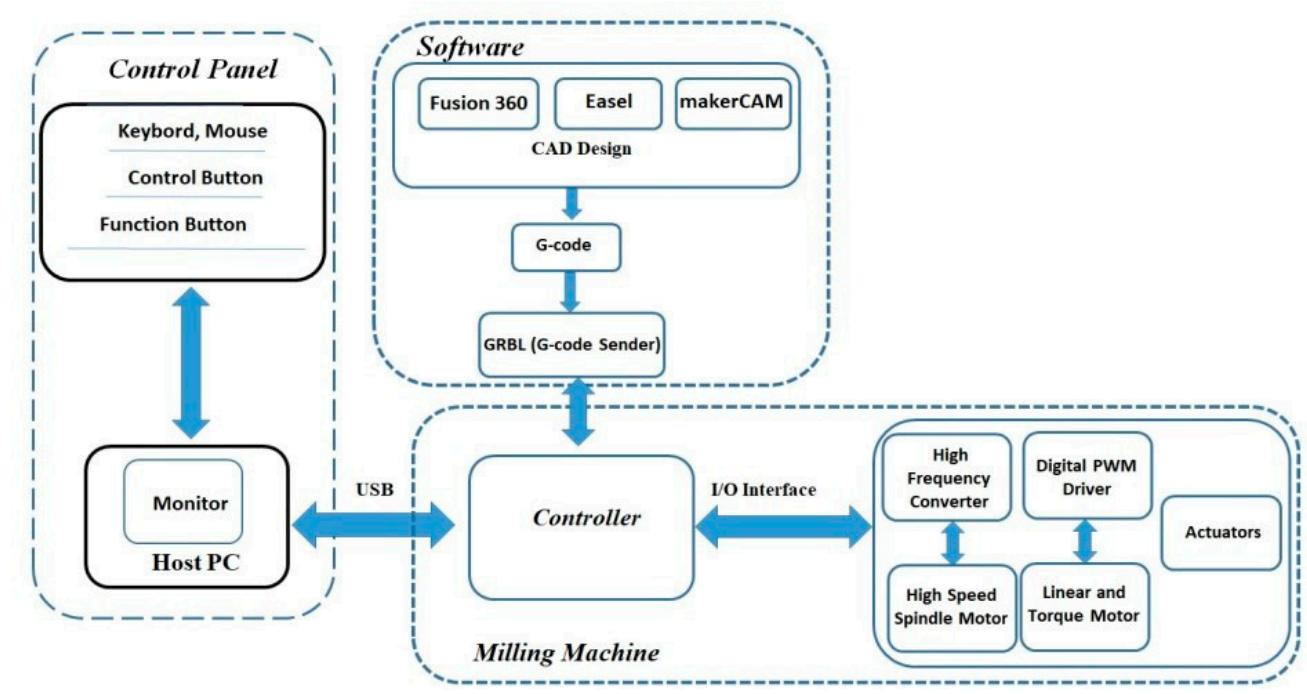

Figure 1. Diagram showing all the necessary components of the milling machine.

Figure 2a shows a schematic diagram of the structure of the proposed milling machine with its dimension. The machine has the dimension of $550 \times 430 \times 330 \mathrm{~mm}$. Figure $2 \mathrm{~b}$ is the picture of the complete setup of the machine that includes a Laptop for designing and sending command, an Arduino based control circuit which is connected to the laptop through USB, motors that are 
interfaced to control circuit, and a drill machine for drilling features. Drill bits of different diameters have been used for drilling and cutting purpose. The maximum resolution of the machine is 18.75 micron in $\mathrm{X}$ and $\mathrm{Y}$-axis and 12.5 microns in Z-axis. The average speed into these three directions are 123.6 RPM and the speed of the spindle is 2500 RPM. The motion accuracy has been estimated to be $50 \mu \mathrm{m}$.

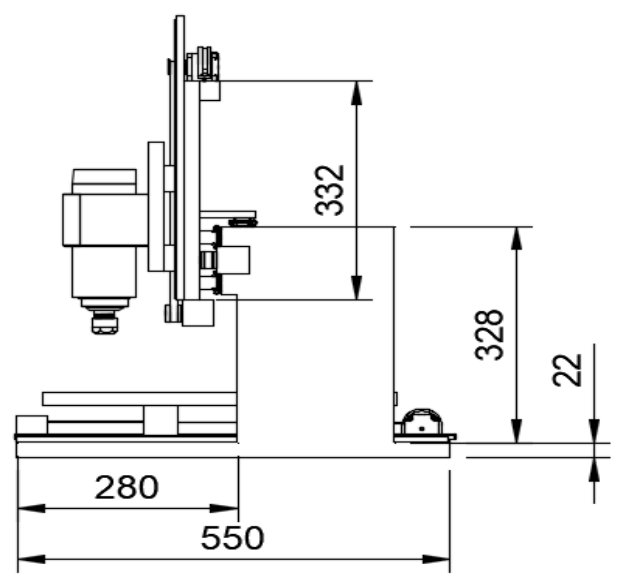

(a)

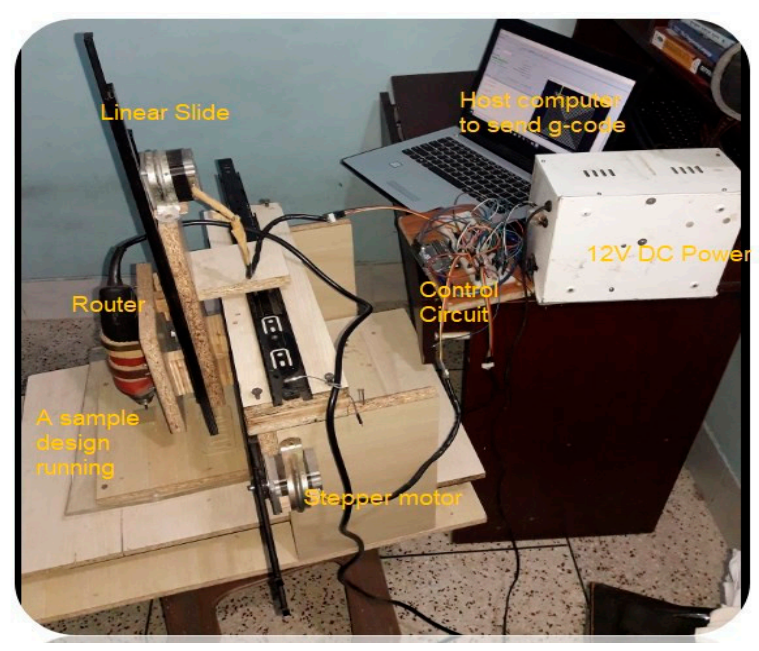

(b)

Figure 2. (a) Schematic of the CNC Milling Machine designed using AutoCAD 360; (b) Picture of the CNC Milling Machine with complete setup.

\section{Results}

The newly developed micro milling machine has been used for the fabrication of some sample features on PMMA materials. Figure 3a shows the diagram of the microchannels designed using computer-based tools. The designed features have then been transferred to the PMMA plastic with the help of the proposed low-cost micro milling machine as shown in Figure 3b. Different drills (2 $\mathrm{mm}, 3 \mathrm{~mm}, 4 \mathrm{~mm}, 0.4 \mathrm{~mm}, 0.7 \mathrm{~mm}$ ) have been used for the evaluation purpose. The machine has demonstrated good accuracy in drilling target depth ranging from $1 \mathrm{~mm}-8 \mathrm{~mm}$ (Figure 4). Accuracy in drilling different levels of depth have been assessed using Digital Vernier Caliper. The average error in the measured depth has been calculated to be $7 \mu \mathrm{m}$. The surface roughness of the fabricated features has also been evaluated using Digital Measuring indicator (Model No.: 2101-10A, Insize electronic). The roughness on a sample of $20 \mathrm{~mm}$ long surface with an interval of $10 \mu \mathrm{m}$ of displacement has been found to be $+/-10 \mu \mathrm{m}$ (Figure 5).

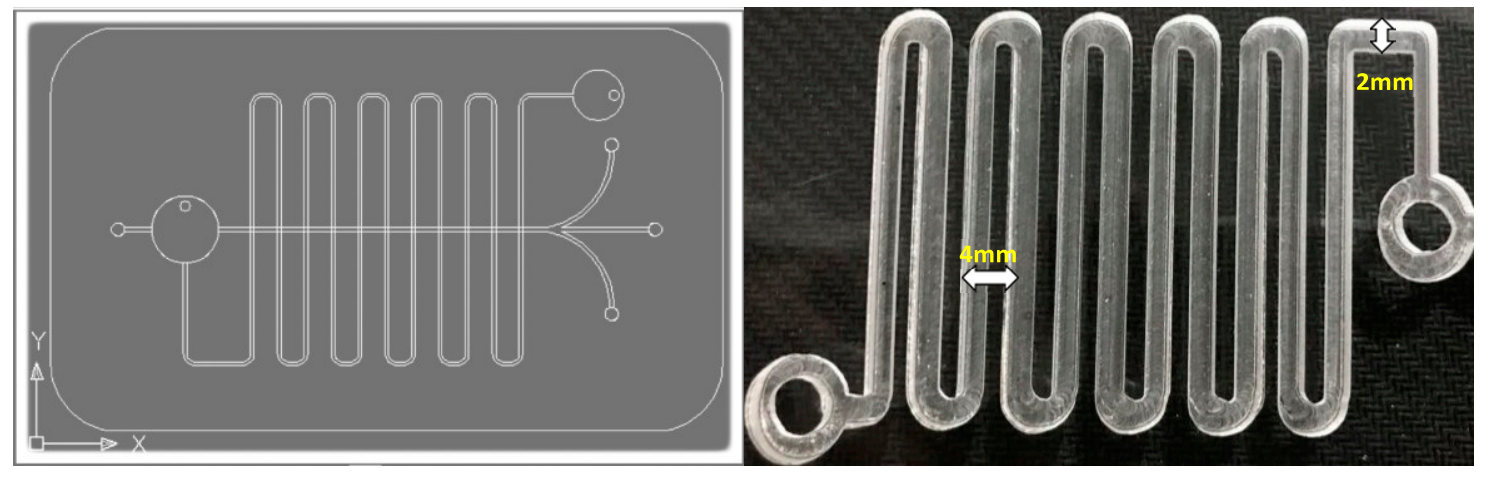

(a)

(b)

Figure 3. (a) Design of the microchannel features using computer-based tools; (b) microchannel features transferred to PMMA using $2 \mathrm{~mm}$ drill with the help of CNC Micro Milling machine. 


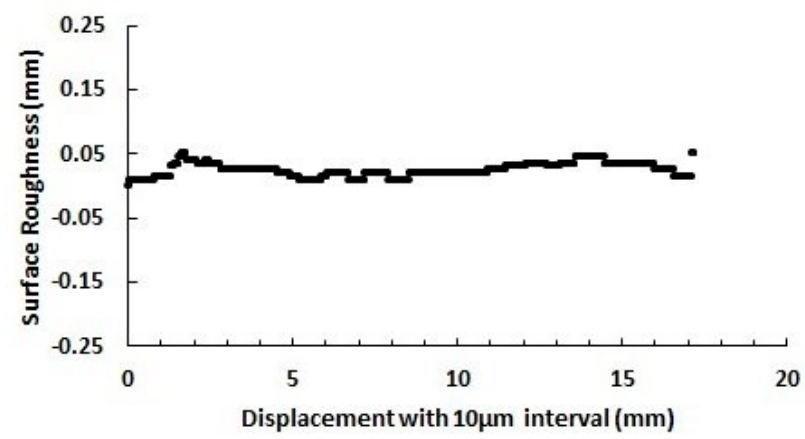

Figure 4. The surface roughness of the fabricated device with a displacement of $10 \mu \mathrm{m}$ on a $20 \mathrm{~mm}$ long surface.

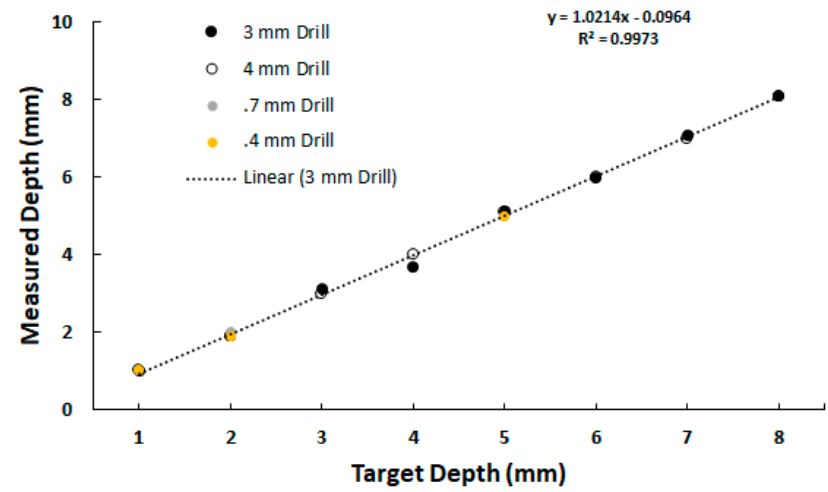

Figure 5. Accuracy in drilling different target depth ranging from $1 \mathrm{~mm}-8 \mathrm{~mm}$ using multiple drills.

\section{Conclusions}

A micro milling machine is an important tool for research and development in the field of clinical and bioengineering. The fabrication of the device itself consumes a significant amount of money of the total research budgets. Here, we propose a locally made and affordable micro milling machine with good accuracy and rapid prototyping ability. If commercialized through the local industry, these kinds of tools may encourage more researchers in the developing country to engage in microfluidic cell biological research.

\section{References}

1. Bhatia, S.N.; Ingber, D.E. Microfluidic organs-on-chips. Nat. Biotechnol. 2014, 32, 760-772.

2. Squires, T.M.; Quake, S.R. Microfluidics: Fluid physics at the nanoliter scale. Rev. Mod. Phys. 2005, 77, 977.

3. Guckenberg, D.J.; de Groot, T.E.; Wan, A.M.; Beebe, D.J.; Young, E.W. Micromilling: A method for ultrarapid prototyping of plastic microfluidic devices. Lab Chip 2015, 15, 2364-2378.

4. Yen, D.P.; Ando, Y.; Shen, K. A cost-effective micromilling platform for rapid prototyping of microdevices. Technology (Singap. World Sci.) 2016, 4, 234-239, doi:10.1142/S2339547816200041.

5. Tanaka, M. Development of desktop machining microfactory. Riken Rev. 2001, 34, 46-49.

6. Kussul, E. Development of micromachine tool prototypes for microfactories. J. Micromech. Microeng. 2002, $12,795-812$.

(C) 2018 by the authors. Licensee MDPI, Basel, Switzerland. This article is an open access article distributed under the terms and conditions of the Creative Commons Attribution (CC BY) license (http://creativecommons.org/licenses/by/4.0/). 